\title{
Homes or Just Houses: The Housing Needs of Female-Headed Households in Egypt
}

\author{
Reem Hamad, Ahmed S. Abd Elrahman, Ayat Ismail \\ Department of Urban Planning and Design, Faculty of Engineering, Ain Shams University, Cairo, Egypt \\ Email: reemkhaledattia@gmail.com
}

How to cite this paper: Hamad, R., Abd Elrahman, A.S. and Ismail, A. (2018) Homes or Just Houses: The Housing Needs of Female-Headed Households in Egypt. Journal of Building Construction and Planning Research, 6, 138-150.

https://doi.org/10.4236/jbcpr.2018.63010

Received: June 19, 2018

Accepted: September 14, 2018

Published: September 17, 2018

Copyright $\odot 2018$ by authors and Scientific Research Publishing Inc. This work is licensed under the Creative Commons Attribution-NonCommercial International License (CC BY-NC 4.0). http://creativecommons.org/licenses/by-nc/4.0/

\begin{abstract}
With the drastic rise in divorce rates in Egypt in the last few decades, targeting female-headed households as new housing segment is becoming increasingly crucial. Female-headed households are categorized as part of the housing vulnerable groups supported by the government. The housing needs, preferences and the market navigation patterns of this group are the study matter of this paper. While this group shares similarities in the housing needs with the two-parent families there are defined differences in the housing presences and market navigation patterns of the two groups. The paper also sheds the light on how the social characteristics of the female-headed households determine the housing problems they face with the current market offerings. Then, it outlines a typology of the housing preferred by the female heads, with the aim of generating recommendations that would help create more inclusive and satisfactory housing market offerings tailored for them. The proximity of the workplace to the housing unit in addition to the presence of an active community center within the neighborhoods was on top of their housing demands.
\end{abstract}

\section{Keywords}

Female-Headed Households Housing, Social Housing in Egypt, Socially Integrated Neighborhoods, Female-Headed Households Inclusive Neighborhoods

\section{Introduction (Female-Headed Households in Egypt)}

Female-headed households (FHH) of divorcees and widowers are considered as part of the vulnerable social groups in Egypt representing $17.8 \%$ of the Egyptian households, this number is increasing rapidly as the average divorce rate recorded in 2015 was $4.7 \%$ for every 1000 people [1] [2] [3]. This rapid increase in 
the percentage of female-headed households made the Egyptian government along with international bodies and organizations of civil society study the demographics of this group and their socioeconomic situation. However, the housing laws and policies aren't yet tailored to accommodate the specific needs of female-headed households and the housing offerings are narrow and don't fulfill the specific needs of this group.

The housing needs and situations of the female-headed households differ according to their locations in different areas in Egypt as their housing characteristics are affected by their place of residents. According to Egypt's latest 2016 census, 238,305 families in urban areas are headed by a single adult parent, $55 \%$ of them are females. Figure 1 below shows the distribution percentages of the female-headed households in urban areas among Egypt's governorates in 2006 \& 2016 respectively [4].

As shown in the map below the female-headed households percentage in big cities like Cairo, Giza, and Alexandria increased drastically as the number of female-headed households was doubled between 2006 and 2016, while the percentages in cities like Sharqia, Qaluibia, Beheria, Menia, and Souhag decreased. Figure 2 below, shows the change in the percentages of the female-headed households in Egypt in the last decade.

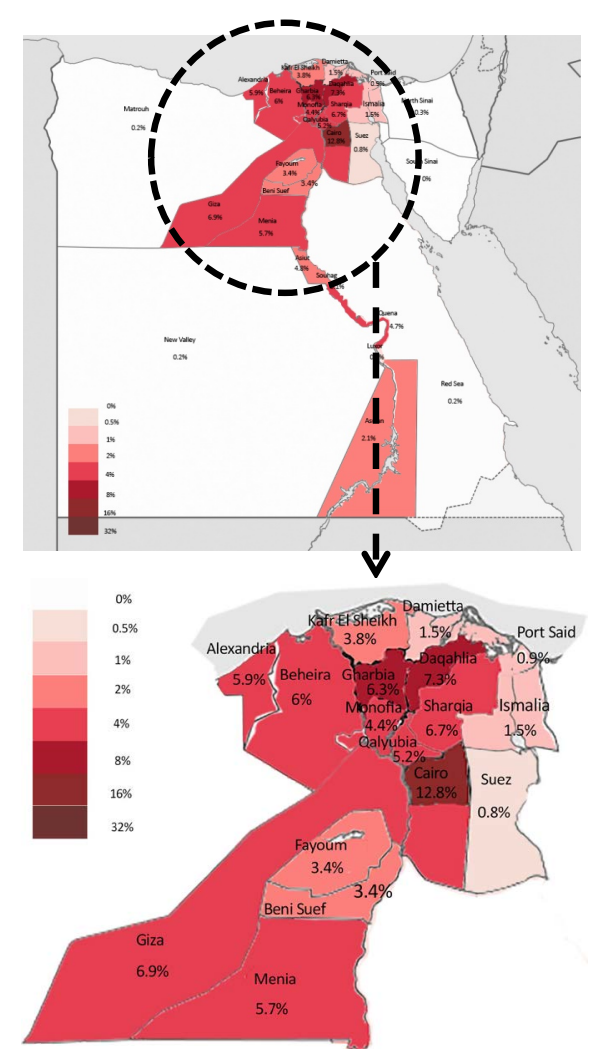

(a)
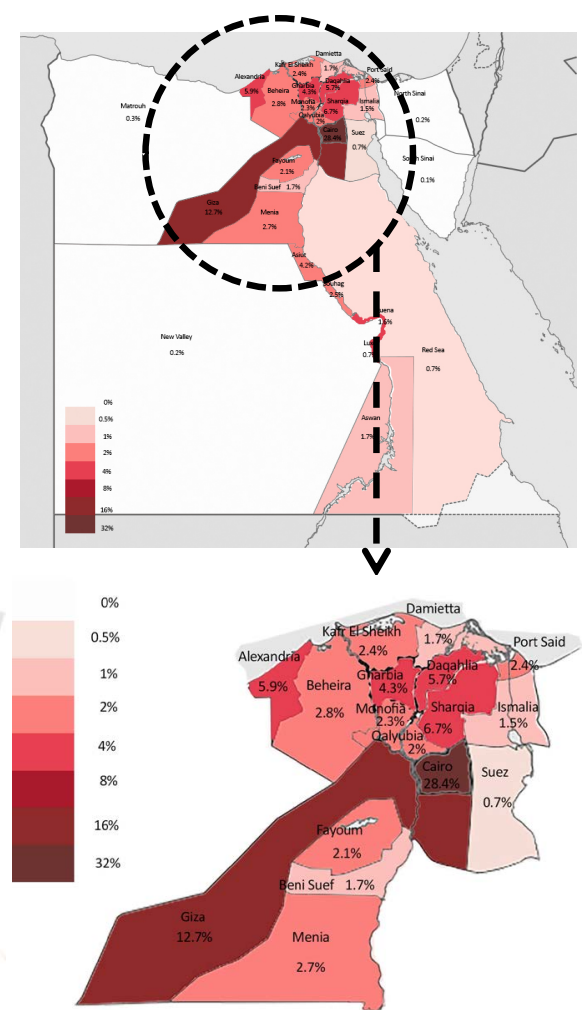

(b)

Figure 1. (a) Female-headed households 2006 percentages among Egypt's governorates; (b) Female-headed households 2016 percentages among Egypt's governorates. Source: Author based on CAPMAS 2006 \& 2016 census. 


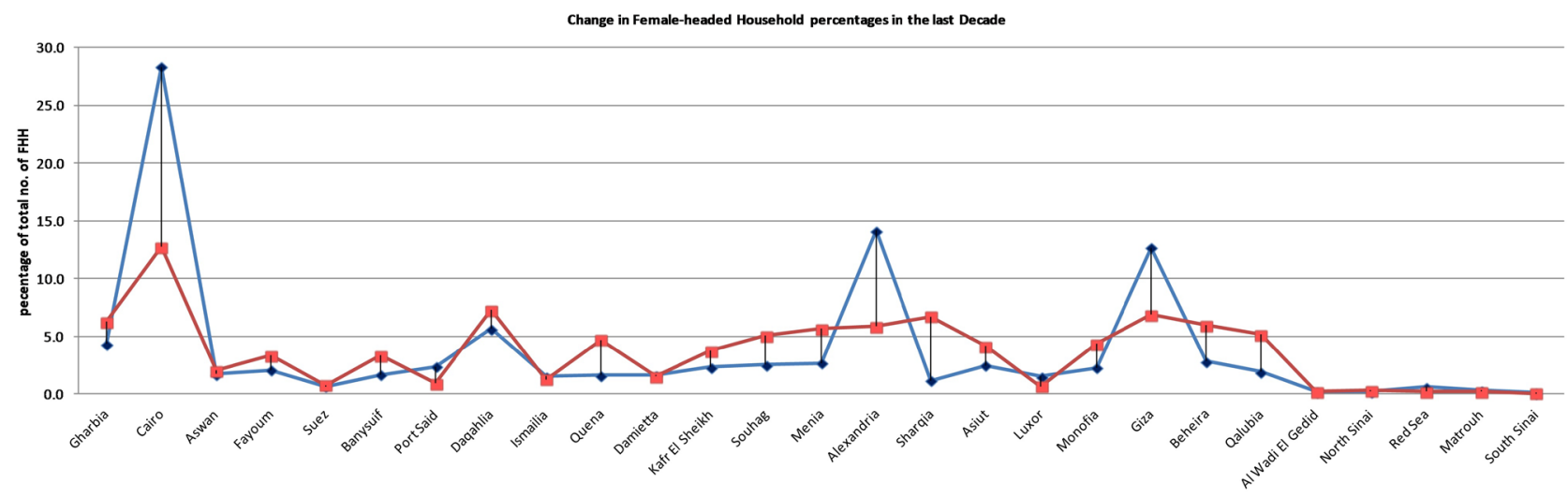

Figure 2. Change in female-headed households percentages in the last Decade. Source: Author based on CAPMAS 2006 and 2016 census.

In Egypt's 2030 vision one of the main urban challenges is the lack of the available proper housing options provided by the government for vulnerable housing groups including female-headed households [5]. The motivation of this paper was the fact that there are no proper housing options targeting the female-headed households as well as the fact that most of the research about the female-headed households' housing preferences was not urban oriented. The paper attempts to find out the housing needs of the female-headed households group in Egypt and how can these needs be translated into physical design options.

\section{What Are the Egyptian Housing Market Offerings for Female-Headed Households?}

\section{Overview of the Egyptian Market Offerings}

In Egypt, housing provision is mainly related to economic and affordability factors neglecting the social situation of different groups. Female-headed households are a vulnerable group that mainly suffers from social vulnerability rather than economic one; however, the government housing plans target them as part of the vulnerable groups who suffer from housing affordability problems ignoring the social needs in housing.

The public sector is responsible for providing housing for the vulnerable groups in Egypt including female-headed households. The Ministry of Housing Utilities and Urban Development and other governmental entities work on establishing social housing units all over Egypt governorates, each vulnerable group is given a share of the established social housing project. The average share of the female-headed households is $5 \%$ of the units dedicated to all the vulnerable groups, including people with disabilities, elders, and low-income families. At the beginning of this year Ahram online the official government newspaper published interviews with housing experts to assess the social housing situation in the past 4 years. Hani Younis, the ministry of housing spokesperson, declared that the offered units are now 90 square meters instead of 60 
square meters, fully furnished. He added that part of the units is rental and the other part is ownership units paid for through mortgage system. The applicant pays 11,000 L.E as a down payment and 400 - 900 L.E monthly installments up to 20 years. The Head of Real Estate Investment division at The Central Bank of Egypt stressed on the need to involve the private sector in the social housing provision as the public sector wouldn't be able to satisfy the demand for social housing. He added that the ministry of housing offered lands at very low prices for private sector developers to build social housing units in exchange for plots for investment, however, the developers were reluctant and no one stepped to buy the lands [6] [7].

\section{Female-Headed Households Housing Situation in Egypt}

\subsection{Research Questions}

1) How do female-headed households of divorcees and widowers deal with their housing demands and navigate the housing market? And what are the housing problems they face?

2) How does the housing preferences and residential experience of female-headed households differ from two-parent families?

3) How can the Egyptian Housing market be more inclusive to female-headed households?

\subsection{Research Design}

Satisfaction surveys and interviews were used to investigate the housing needs and preferences of female-headed households. The paper tackles three main questions. Focus group interviews with 520 Egyptian female heads were used to answer the first question regarding the female-headed households housing demands, preferences and problems they might face while navigating the housing market. The interview with the female heads was divided into two parts; problems female-headed households have with the Egyptian housing market offerings and the female heads housing suggestions to overcome these problems and have a more inclusive market. To answer the second question a random housing survey was carried out with 193 people to inquire about their housing preferences and then compare the answers with the female heads' answers. Finally, in-depth interviews with 6 Egyptian housing experts were conducted to provide an understanding of the problems female-headed households face with the current market offerings and the housing models suitable for their needs.

\subsection{Methods}

The interviews with the female heads were conducted online, in addition, planned in-depth interviews with some of the female heads who have no online access. The interviews were carried out in Arabic to facilitate the communication and comprehension. The survey about the housing preferences was online directed to a random sample of people. The interviews with the Egyptian housing 
experts were in prearranged meetings, both of the surveys and the interviews were conducted in English.

\subsection{Interview Description}

The focus group questions were open-ended questions formulated on three sets urban planning, urban design and architecture to assess the quality of the offered housing units and the satisfaction of the female heads with the housing units. At the end of each set, the female heads were asked about their suggestions to improve the market offerings. The survey questions were closed-ended questions regarding housing preferences. The questions directed to the experts were more specifically oriented towards the ways of building female-headed households inclusive neighborhoods in Egypt.

\section{Sampling and Data}

The study group sample was a stratified random sample, the below Table 1 shows the demographic data of the study group:

\section{Results and Discussion}

\subsection{How Do Female-Headed Households of Divorcees and Widowers Deal with Their Housing Demands and Navigate the Housing Market? And What Are the Housing Problems They Face?}

The female-headed households talked about their housing problems with the current market offerings, the result showed that $49 \%$ of the respondents suffer from limited access to housing units offered by the government; they criticized the announcement process and they stated "Most of us don't have a clue about the units and the application criteria" [8].

$14 \%$ of the female heads who were aware of the units and tried to apply for them had problems with the application's terms and conditions; they expressed their discontent with some of the conditions like being divorced for 7 years minimum, they said "Why being divorced for 7 years is one of the conditions to apply for the subsidized housing unit?" [9]. They also talked about the limited

Table 1. Demographic data of the study group.

\begin{tabular}{|c|c|c|c|c|}
\hline \multirow{2}{*}{ Number } & \multicolumn{3}{|c|}{ Characteristics } & \multirow[b]{2}{*}{ Place of residence } \\
\hline & Marital Status & Age range & Economic class & \\
\hline 145 & Divorced/Widow & $25-45$ & Middle class & Giza \\
\hline 191 & Divorced/Widow & $30-55$ & Middle class & Cairo \\
\hline 145 & Divorced & $35-50$ & Lower middle class & Other governorates \\
\hline 100 & Married & $25-45$ & $\begin{array}{c}\text { Upper middle } \\
\text { class/middle class }\end{array}$ & Cairo, Giza \\
\hline 107 & Single & $22-35$ & $\begin{array}{c}\text { Upper middle } \\
\text { class/middle class }\end{array}$ & Cairo, Giza \\
\hline
\end{tabular}

Source: Author based on the interviews. 
number of units due to the fact that most of the offered units are part of big social housing project targeting all vulnerable groups with only $5 \%$ share dedicated to female-headed households.

On the other hand, female heads living in private sector housing stated that their access to housing problems are affiliated to their marital status as the majority of the landlords fear to rent housing units to divorcees and widowers thinking that it might have a bad influence on the building reputation.

The lack of social interaction and community support was the second rated housing problem the respondents mentioned, $20 \%$ reported that the lack of community support amplifies the hardship of the female heads' role. They explained that a female head who is obliged to work and raise kids deserves a supportive neighborhood in which people can depend on each other and do activities together which would facilitate her daily tasks and add up to the neighborhood security.

The services was another problem that $10 \%$ of the female heads considered as their main housing problem, they had a problem with the quality of the provided services in addition to the far location of the units which hindered them from finding a nearby substitute. The far units' location resulted in accessibility and transportation problems, a number of the female heads stated "we would rather live in a room on the roof near the metro than living in these offered units in the desert" [10].

Others who can't afford to rent units in areas near the city center talked about their attempts at finding home based jobs. Another problem the female heads addressed in the interviews was the apartment size, they were more satisfied with the smaller areas provided by the government targeting female-headed households only but recently most of the government projects provide standardized sizes as they are targeting all vulnerable groups together which they considered a problem [11].

The below Figure 3 summarizes the problems the female heads face with the Egyptian housing market. They had two main problems with the quality of the provided services like the proximity of the housing unit to the work place, the proper public transportation... etc. The other problem was their constrained access to the housing units and the arbitrary application terms and conditions.

\subsection{How Does the Housing Preferences and Residential Experience of Female-Headed Households Differ from Two-Parent Families?}

To answer this question regarding the differences between the female-headed households' residential experiences and the two-parent families, we will display the results from the random survey about the housing preferences, the preferences of groups other than female-headed households aren't the focus of this papers however the survey could give an indication of the current housing demand and market orientation. The survey gave an indication to the current housing needs and demands of Married couples and single individuals, the profile of the most wanted housing unit according to the survey is: 


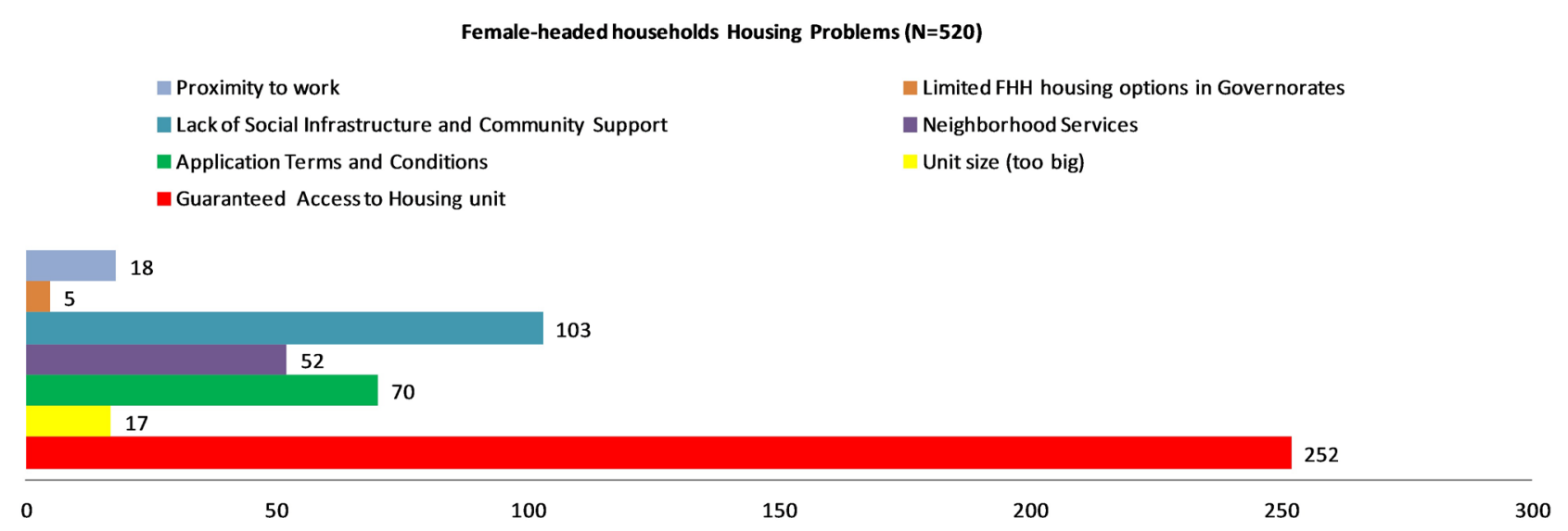

Figure 3. Female-headed households' Housing Problems. Source: Author based on the interviews.

- Owned ( $80 \%$ of the respondents)

- Located in suburbs (63\% of the respondents)

- Services within a walking distance ( $86 \%$ of the respondents)

- Near public transportation hub (76\% of the respondents)

- In a gated community (65\% of the respondents)

The survey results were as expected as most of the private real estate companies' housing investments in Egypt are directed towards the creation of gated communities targeting upper class, upper middle class, and few investments are targeting the middle class. This result resonates with the earlier mentioned statement about the reluctance of the private sector to invest in social housing as the demand is high for the owned units and the compounds which are more profitable [12]. Figure 4 shows the orientation of the private sector towards the gated communities.

On the hand when the female-headed households were asked about their housing preferences and the profile of the female-headed households supporting neighborhoods, they expressed their dissatisfaction with the current housing offerings saying that they can't find a place for them in the current housing market. They added that their economic and social vulnerability constrain their options, however they shared common housing preferences, most of the female heads preferred rental units over owned one for affordability reasons but also some of them added that the rental units give them more chances to upgrade or downgrade according to the change in their social and economic state. They believed that living in the city center is more suitable for them as they offer a wide range of services and transportation options. The female heads see that private sector offerings aren't affordable or suitable for them and they have problems with government offerings so when talking about their preferences they described more compact and mixed-use designs that were not found [13].

\subsection{How Can the Egyptian Housing Market Be More Inclusive to Female-Headed Households?}

To answer the third question the female heads and Egyptian housing experts 
were asked about their suggestions to create room for female-headed households in the Egyptian housing market.

\subsubsection{Female-Headed Households Suggestions}

After expressing their dissatisfaction with the market offerings the female heads shared their ideas and suggestions to improve the market offerings to become more inclusive of the female-headed households' needs. $96 \%$ of the respondents suggested that the government and the private sector should develop plans to provide housing units targeting female-headed households as a separate housing segment, not as part of the vulnerable groups. While $2 \%$ of them were uncertain about this idea and thought that the government and the private sector wouldn't bother targeting female-headed households as a separate housing segment. A focus group was held with 137 female heads that had ideas about improving the female-headed households housing situation in Egypt. The below Figure 5 demonstrate the top suggestions which were mentioned several times by the female heads [14] [15] [16].

Cooperative Housing

$38 \%$ of the female heads talked about the idea of female-headed households living together in the same building helping each other with their daily chores and rearing the children, they imagined a group of female-headed households living in one building like students dorms. After hearing this idea a multiple times in the interviews I decided to show them a picture of a co-living diagram developed by Improvistos Figure 6(a) which illustrates how housing units can be adaptable and elastic to suite the changing life style of the household. The co-living idea is based on providing shared services like common kitchen, laundry, workshops for the housing units within the same building to encourage the interaction between the residents and strengthen the sense of community support. The female heads were satisfied with the idea and thought that it is somewhat similar to what they had in mind; they all believed that no one could understand their conditions except for themselves; therefore, they will be each other's best support.

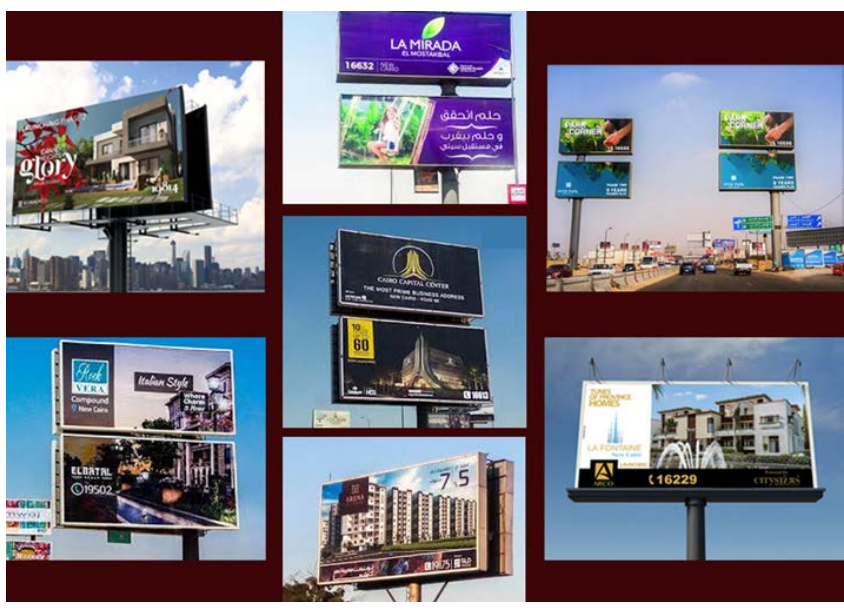

Figure 4. Compound billboards covering the streets of Egypt. Source: Author. 


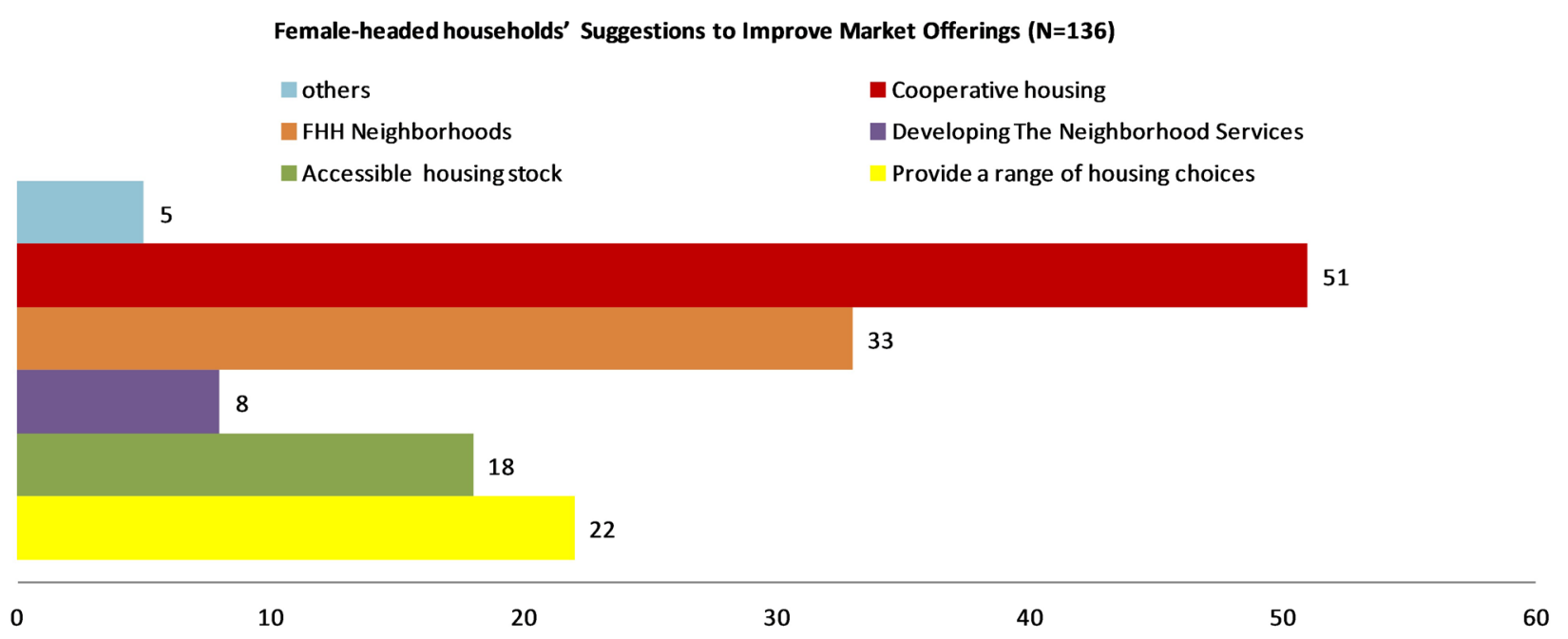

Figure 5. Female-headed households housing suggestions to improve market offerings. Source: Author based on the interviews.

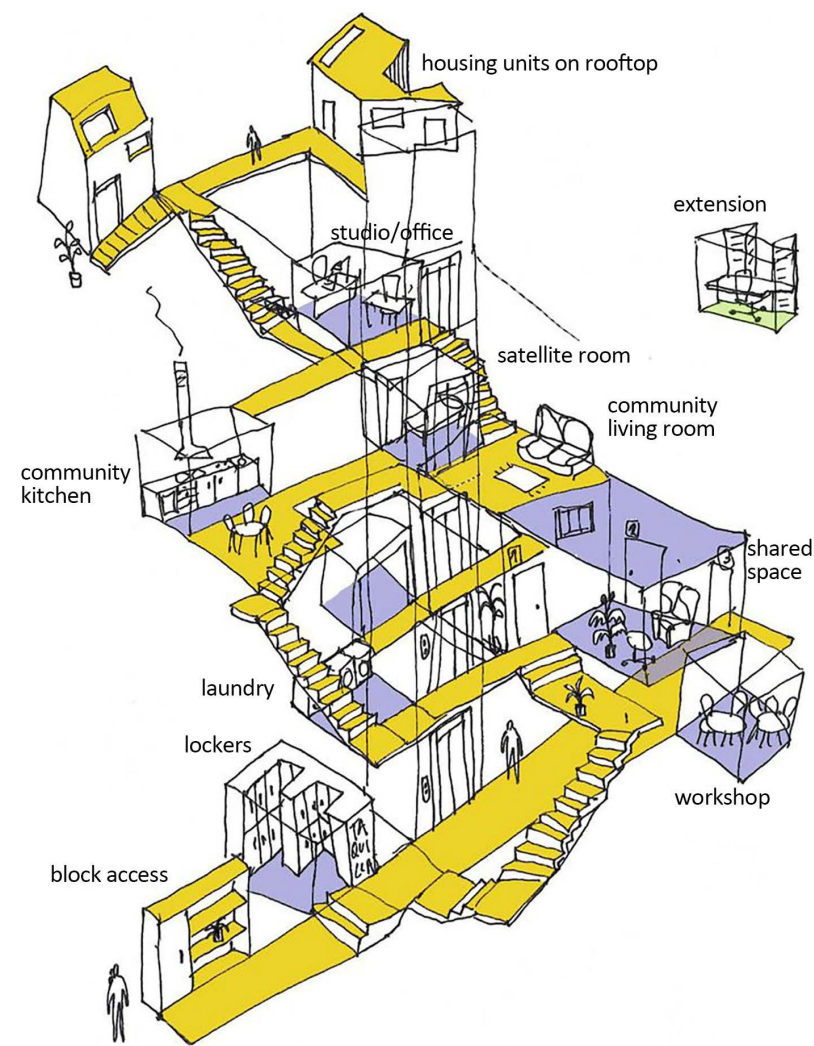

(a)

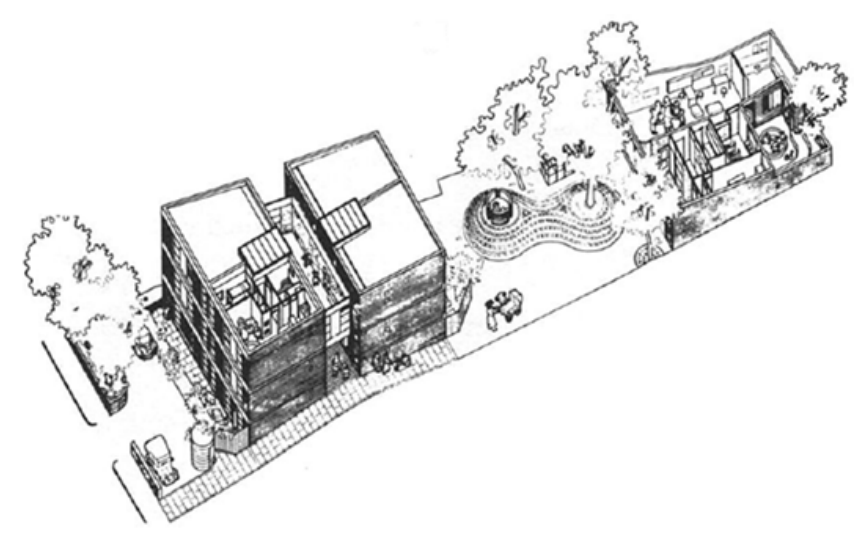

(b)

Figure 6. (a) Co-living diagram; (b) Fiona House, London. Source: Improvistos 2015; Hayden 1980.

In the housing literature cooperative housing was represented a successful approach to target female-headed households, one of the earliest applications was the Fiona house in London shown in the below Figure 6(b). The project was designed by Sylvester Bone in 1972 targeting divorced and separated mothers; it consisted of twelve two-bedroom units connected by an intercom system for baby-sitting, a playground area and a neighborhood nursery facility [17]. 
Female-headed households Neighborhoods

The majority of the female heads postulated that they can be each other's support. $24 \%$ of the respondents suggested building neighborhoods for female-headed households. They agreed on establishing an organization through which they can buy two neighboring lands by collecting money from the members. They discussed starting off by assigning different tasks among the members; each group of members will be responsible for a certain task according to their fields of expertise. One of the responding female heads who is also a lawyer added that the Egyptian law allows these projects under two conditions, which are that the organization must have a headquarter office and a minimum listed number of members.

Rehabilitation of the current housing stock

Part of the female heads' suggestions was directed towards the rehabilitation of the current housing stock to fit the female-headed households housing needs and solving the problems female-headed households face with the offered housing units. The female heads stated that guaranteed access to the housing stock is one of the top priorities for female-headed households seeking a housing unit. They put forward that transparency is needed when announcing for new housing units; the information should be available and a clear instructive public announcement should be made using media and newspapers.

They added, there must be a variation in the housing prototypes offered by the government or the private sector, they suggested that the government and the private sector should consider assigning part of the housing project designs to suit the female-headed households needs. One of the suggestions was to offer studio apartments with different payment methods near playing areas for children. The female heads stressed on the importance of the neighborhood services and how the private and public sector work on enhancing the quality of the provided services, they suggested extending the working hours of some services such as nurseries and clinics and adding supportive community center in each district.

\subsubsection{Experts' Opinion}

After the interviews with the female heads, 6 interviews were conducted with Egyptian experts who work in the field of housing and planning in Egypt and took part in some of the government's housing targeting female-headed households. The experts described the Egyptian housing market as a Typical Family Oriented Market that doesn't respect the life cycle of the residents as it doesn't offer units with different sizes and payment options to suit different types of families and individuals. They claimed that the female-headed households housing needs are overlooked by the public and private sectors' housing developers, they said as the female-headed households housing vulnerability isn't yet understood by the market as their needs seem to be similar to the basic housing needs of any other group. The housing units provided for vulnerable groups including female-headed households are built in new communities usually with no 
proper accessibility or public transportation which encourages the informal transportation solutions like (micro-buses and tuk-tuk). Moreover, the new cities and service facilities in most cases are built together as planned but the residents start living in the units with no facilities for a while as the service facilities take a long time to function due to the lack of manpower. The new cities 'services miss an important service factor which is craftsmen provided services the absence of a nearby plumber, electrician, mechanic... etc. causes a problem for household especially female-headed households.

The experts explained their different opinions' on how the housing market could lobby the needs of the female-headed households, a comprehensive plan to target each group of the female-headed households groups separately would lead to higher rates of residents' satisfaction and projects success. The interviews can be summarized in design considerations that should be taken on the architecture, urban design, and urban planning levels.

Architecture level: the units have to be small in size with minimum waste areas; the government made a $35 \mathrm{~m}^{2}$ prototype for female-headed households long time ago which was very convenient.

Urban design level: the neighborhood services should include a community center to act as an umbrella for the female-headed households to provide services for female heads like a $24 \mathrm{hrs}$ working nursery, a database for all nearby craftsmen, provide mental support and life coaching sessions, workshops... etc. The community center must have a strong administration headed by women association and should be given authority from the district to be able to regulate the services and the maintenance in the neighborhood. The community centers should be built in areas with a high number of female-headed households or on a district level if the numbers are low.

Planning level: the female-headed households housing units' proximity to their work is a very important aspect; to design a new city this aspect would affect the future of the city design. An example of this is found in a village in Assiut where female heads were given workshops about handmade carpets and how to make them organized by the government and a carpet factory. The female heads of the village were given the tools and were employed by the factory. This example is found in many of Egypt's rural areas.

The process would be more complicated in urban areas but applicable. A study showing the most common profession in the urban area along with a vocational education center for female-headed households would be required. This would create an opportunity for female heads to work near their homes. In order to facilitate and rapid the functioning of services in new cities, a modification in the city's administrative system should be made. A good example is how they manage new cities, abroad by assigning a key person to be the head of the city to be responsible for managing the city facilities and make sure that the city is functioning properly [18] [19] [20].

The experts mentioned in the interviews a number of drawbacks regarding the 
Egyptian market offerings which were verified by field visits to some of the housing projects. There was a serious problem with the sites' accessibility as it took a long time to find a transportation method heading there. Also, the lack of pre-planned service areas led to the emergence of unplanned services within the residential areas.

\section{Conclusions}

The research suggests some interesting findings about the female-headed households' group in Egypt. The female heads are very aware of their housing problems and needs and many of their suggestions could be easily translated into actual design solutions. There were considerable similarities between the housing preferences of the female-headed households and the two-parent families when it comes to the basic housing needs such as good public transportation and accessible services within walking distance. Such basic needs are lacking in most of the market offerings targeting the female heads.

Female-headed households are offered few choices of new housing as their marital status and affordability problems affected their housing situation and resulted in their elimination from the private sector target list. Moreover, the public sector investments are mostly oriented towards the low-income families. Another point worth noting is that a large number of the female-headed households deflect away from the public sector offerings because of services and accessibility problems. In some cases, it appeared that the female-headed households are satisfied with living in areas that have services and accessibility issues as they have found compensation in the quality of the public realm as well as the community support and acceptance.

The female heads and the experts agreed on some essential requirements for the housing of female-headed households. These requirements include proximity of the housing unit to the workplace of the household head as well as the incorporation of supportive community centers within the neighborhood.

Finally one of the major findings was the importance of considering the social environment and support while targeting groups that suffer from social vulnerability such as female-headed households, and realizing that targeting these groups using Physical design-oriented solutions alone is not enough.

\section{Conflicts of Interest}

The authors declare no conflicts of interest regarding the publication of this paper.

\section{References}

[1] CAPMAS (2006) Female-Headed Households Percentages in Egypt's Governorates. CAPMAS, Cairo.

[2] CAPMAS (2014) 2014 Statistical Report. CAPMAS, Cairo.

[3] CAPMAS (2015) Divorce Rates in Egypt Census 2015. CAPMAS, Cairo. 
[4] CAPMAS (2017) 2016 Egypt's Population Census. CAPMAS, Cairo.

[5] GOPP (2016) Egypt's 2030 Vision: Urban Development Pillar. GOPP, Cairo.

[6] Mounir, S. (2018) Social Housing: Better Homes in Egypt. http://english.ahram.org.eg/NewsContent/1/1189/291088/Egypt/ElSisis-Balance-Sh eet/Social-housing-Better-homes-in-Egypt.aspx

[7] New Urban Communities Authority (2016) New Urban Communities Portal. http://www.newcities.gov.eg/english/default.aspx

[8] FH1 (2017) Problems Female-Headed Households Face in the Egyptian Housing Market.

[9] FH2 (2017) Application Process.

[10] FH3 (2016) Female Downshifters' Housing Problems.

[11] Female-Headed Households (2017) Housing for Female-Headed Households of Divorcees and Widowers.

[12] Two-Parent Families \& Singles (2018) Housing Preferences.

[13] Female-Headed Households (2017) Problems with Current Housing Supply.

[14] Female-Headed Households Focus Group (2017) Suggestions to Improve the Egyptian Housing Market Offerings.

[15] Improvistos (2015) Improvistos. http://www.improvistos.org/en/home/

[16] Fainstein, S.S. and Servon, L.J. (2005) Gender and Planning. Rutgers, London.

[17] Hayden, D. (2008) What Would a Non-Sexist City Be Like? Speculations on Housing, Urban Design and Human Work. The University of Chicago Press, Chicago.

[18] Kamal, A. (2018) Vulnerable Groups and Female-Headed Households Housing Situation in Egypt.

[19] Saleh, E. (2018) Neighborhoods for Female-Headed Households.

[20] Shedid, Y. (2017) Neighborhood for Vulnerable Groups. 